development, meaning the effects seen here could be relevant to this process.

A final insight from this report is the observation that there is a cell-deformation threshold at which stem-cell differentiation is induced. Force-induced conformational changes of key adhesion proteins ${ }^{11,12}$ have been observed and a specific amount of force acting on the cell is required to induce the change. It seems as though cyclic stress may have induced such a change, or at least caused the phosphorylation of a part of the cells' myosin proteins; myosin is a motor protein, and its phosphorylation is an important step in cells generating and responding to forces. If cells were too stiff to be deformed in this manner, these proteins would be unable to experience the force necessary to unfold, and therefore could not convert the physical stimulation of active cyclic stress into chemical signals controlling differentiation. Intuitively, the soft nature of embryonic stem cells is therefore an indispensable intrinsic material characteristic that will require substantial further exploration.

Andrew W. Holle and Adam J. Engler are in the Department of Bioengineering, University of California, San Diego, La Jolla, California 92093, USA.

e-mail:aengler@ucsd.edu
References

1. Engler, A. J., Sen, S., Sweeney, H. L. \& Discher, D. E. Cell 126, 677-689 (2006).

2. Dalby, M. J. et al. Nature Mater. 6, 997-1003 (2007)

3. Flaim, C. J., Chien, S. \& Bhatia, S. N. Nature Methods 2, 119-125 (2005).

4. McBeath, R., Pirone, D. M., Nelson, C. M., Bhadriraju, K. \& Chen, C. S. Dev. Cell 6, 483-495 (2004).

5. Chowdhury, F. et al. Nature Mater. 9, 82-88 (2010).

6. Wang, N., Butler, J. P. \& Ingber, D. E. Science 260, 1124-1127 (1993).

7. Wang, N., Tytell, J. D. \& Ingber, D. E. Nature Rev. Mol. Cell Bio 10, 75-82 (2009)

8. Katsumi, A. et al. J. Cell Biol. 158, 153-164 (2002).

9. Krieg, M. et al. Nature Cell Biol. 10, 429-436 (2008)

10. Zhou, J., Kim, H. Y. \& Davidson, L. A. Development 136, 677-688 (2009)

11. del Rio, A. et al. Science 323, 638-641 (2009).

12. Johnson, C. P., Tang, H. Y., Carag, C., Speicher, D. W. \& Discher, D. E. Science 317, 663-666 (2007).

\title{
WHY IS BORON SO HARD?
}

Everyone knows about the disputed discovery of oxygen, but it's less widely known that boron is dogged by the same controversy, and with a similar Anglo-Gallic flavour. In this case the rivals were Louis Joseph Gay-Lussac and Louis Jacques Thenard in France and Humphry Davy in England, both of whom announced the discovery in June 1808. Gay-Lussac and Thenard used chemistry (reducing boric acid with potassium, which Davy had reported the previous year), whereas Davy used his trademark method of electrolysis.

However, neither technique produced pure boron. It wasn't until 1895 that Henri Moissan came close to doing that by the reduction of borax with magnesium; but most accounts credit the American chemist E. Weintraub with having made the first 'pure' samples in 1909-1911. Even that is not fully clear, because the first pure boron phase, $\beta-\mathrm{B}_{106}$, was not reported until 1957 (ref. 1).

Much of this confusion arises because boron's chemistry and phase behaviour are extremely complicated - as Artem Oganov and Vladimir Solozhenko argue in a recent paper that revisits this history ${ }^{2}$, it is "arguably the most complex element in the periodic table". Boron forms boron-rich yet stoichiometric compounds with many elements, such as $\mathrm{YB}_{66}, \mathrm{NaB}_{15}$ and $\mathrm{B}_{50} \mathrm{~N}_{2}$, all with complex crystal structures different from those of the pure phases. This has led many scientists astray, beginning with the mistaken assignation by Friedrich Wöhler and Henri Sainte-Claire Deville of diamond-like, graphite-like and amorphous polymorphs analogous to those of carbon ${ }^{3}$.

None of the early boron polymorphs were pure phases. The so-called I-tetragonal phase, recorded in 1943, was considered sufficiently secure to feature 4 in Linus Pauling's The Nature of the Chemical Bond, but is now considered to be a boron-rich carbide or nitride. And of the 16 polymorphs described so far, most are likely to be boron-rich compounds. Only for four of these putative phases are crystal structures known, most of them composed of interlinked $\mathrm{B}_{12}$ icosahedra.

This confusion and uncertainty is all the more surprising as boron is such a potentially useful material. Even in the mid-nineteenth century it was known to be very hard, and the synthesis of cubic boron nitride by researchers at General Electric in the 1950s supplied the main industrial alternative to diamond for cutting tools and abrasion. Robert Wentorf, one of the key players in that work, reported a very hard form of pure boron in 1965 made at high temperature and pressure ${ }^{5}$; but this was neglected until high-pressure phases of boron became fashionable because of their possible superconductivity ${ }^{6}$. And astonishingly, it wasn't until 2007 that the most stable phase of boron under ambient conditions was finally identified ${ }^{7-9}$.

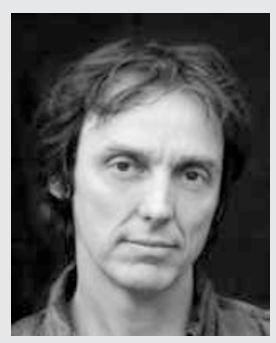

PHILIP BALL

The controversies are by no means over, for the priority for discovery of a new superhard phase of boron, $\gamma-B_{28}$, remains disputed ${ }^{10-12}$. (It seems possible that Wentorf's hard material was an impure form of this one.) The uniqueness of its crystal structure ${ }^{10}$ (no $\mathrm{B}_{12}$ icosahedra) suggests that we may still be only scratching the surface of boron.

References

1. Sands, D. E. \& Hoard, J. L. J. Am. Chem. Soc. 79, 5582-5583 (1957).

2. Oganov, A. R. \& Solozhenko, V. L. J. Superhard Mater. 31, 285-291 (2009).

3. Sainte-Claire Deville, H. \& Wöhler, F. Ann. Physik 176, 635-646 (1857).

4. Pauling, L. The Nature of the Chemical Bond 3rd edn (Cornell Univ. Press, 1960).

5. Wentorf, R. H. Science 147, 49-50 (1965)

6. Eremets, M. I., Struzhkin, V. W., Mao, H. K. \& Hemley, R. J. Science 293, 272-274 (2001)

7. Van Setten, M. J., Uijttewaal, M. A., de Wijs, G. A. \& de Groot, R. A. J. Am. Chem. Soc. 129, 2458-2465 (2007).

8. Widom, M. \& Mihalkovic, M. Phys. Rev. B 77,064113 (2008).

9. Ogitsu, T. et al. J. Am. Chem. Soc. 131, 1903-1909 (2009).

10. Oganov, A. R. et al. Nature 457, 863-867 (2009).

11. Solozhenko, V. L., Kurakevych, O. O. \& Oganov, A. R. J. Superhard Mater. 30, 428-429 (2008).

12. Zarechnaya, E. Y. et al. Phys. Rev. Lett. 102, 185501 (2009). 